\title{
Abscess Within a Brain Metastasis
}

\author{
Wai Pui Ng and Andres Lozano
}

\begin{abstract}
Background: Neoplastic metastases to the cerebellum are a frequent complication in patients with carcinoma. However, the co-existence of an abscess within a CNS metastasis is a rare event. Methods: We report the case of a 79-year-old woman with two cerebellar abscesses within metastatic lesions in the cerebellum. She presented with a rapidly progressing syndrome characterized by elevated intracranial pressure and cerebellar findings. Results: At surgery, a purulent exudate within discrete metastatic tumours was identified. Pathological and microbiological examinations confirmed the coexistence of an abscess within a metastatic carcinoma. Significance and Conclusion: The radiological diagnosis of intracranial abscesses and metastases can be non-specific and brain imaging may not reliably identify both processes when they coexist. Furthermore, brain metastases often contain liquefied material which can be mistaken for tissue necrosis rather than an infectious process. It is important to be aware that a brain metastasis can also be infected. Therefore, acquisition of lesional tissue for both pathological and microbiological examinations is essential for accurate diagnosis and to direct optimal therapy in situations where the intracranial lesion could be either an abscess or a metastatic deposit.
\end{abstract}

RÉSUMÉ: Abcès dans une métastase cérébrale. Introduction: Les métastases néoplasiques au cervelet sont une complication fréquente chez les patients qui sont porteurs d'un carcinome. Cependant, la coexistence d'un abcès dans une métastase cérébrale est rare. Méthodes: Nous rapportons le cas d'une femme de 79 ans qui avait deux abcès cérébelleux dans des lésions métastatiques du cervelet. Elle a présenté un syndrome rapidement progressif caractérisé par une pression intracrânienne élevée et des signes cérébelleux. Résultats: A la chirurgie, on a constaté la présence d'un exsudat purulent dans des tumeurs métastatiques discrètes. L'examen anatomopathologique et la microbiologie ont confirmé la coexistence d'un abcès et d'un carcinome métastatique. Interprétation et conclusion: Le diagnostic radiologique des abcès intracrâniens et des métastases peut être non spécifique et l'imagerie du cerveau n'est pas fiable pour identifier les deux processus quand ils coexistent. De plus, les métastases cérébrales contiennent souvent du matériel liquéfié qui peut être pris à tort pour du tissu nécrotique plutôt qu'un processus infectieux. Il est important de savoir qu'une métastase cérébrale peut aussi être infectée. Il est donc essentiel d'obtenir du tissu pour analyse anatomopathologique et microbiologique afin de poser un diagnostic précis et de cibler le traitement de façon optimale quand la lésion peut être soit un abcès ou une métastase.

Can. J. Neurol. Sci. 1996; 23: 300-002

The cerebellum is a common site of intracranial metastasis, and is the location of $16 \%$ of cases of solitary brain metastasis. ${ }^{1.2}$ Metastatic spread to the cerebellum is usually hematogenous. Abscesses in the cerebellum can also be hematogenous or the result of direct extension of infections in the middle ear or the mastoid with thrombophlebitis of the emissary veins. ${ }^{3-5}$

The management of metastasis and abscess are entirely different. However, intracranial metastasis and abscess can have similar radiological presentations. We are reporting a rare case of an abscess within a cerebellar metastasis in a patient with an infected lung lesion. As this case illustrates, proper diagnosis and treatment require appropriate examinations of the surgical specimens.

\section{CASE History}

A 79-year-old right-handed female heavy smoker presented with a 6 month history of productive cough. Her chest $x$-ray and CT scan showed a right lower lobe cavitary lesion measuring $4 \mathrm{~cm} \times 4 \mathrm{~cm} \times 6$ $\mathrm{cm}$ with right hilar lymphadenopathy and pericarinal nodes (Figure 1).
Repeated bronchoalveolar lavage and brushings revealed only necrotic material but no tumour cells. Percutaneous aspiration of the lung mass produced a purulent exudate which grew bacteroides and diphtheroides species. The patient was started on intravenous ceftazidime and metronidazole. Four weeks prior to admission, she developed headaches consistent with increased intracranial pressure with nausea, vomiting and early morning exacerbation. There was recent deterioration for at least 2 days with intractable vomiting and truncal and limb ataxia which were worse in the left side.

Examination revealed an unwell lady with intractable nausea, severe truncal and bilateral limb ataxia worse in the left side. There were no findings of corticospinal or cranial nerve dysfunction. She did not have papilloedema. Initial laboratory examination showed an elevated white cell count of 15.4 million/l with a granulocytosis.

A CT scan performed after the administration of intravenous contrast material revealed 2 ring-enhancing lesions in the cerebellum

From the Division of Neurosurgery. The Toronto Hospital. University of Toronto. Toronto.

RECEIVED JANUARY 22, 1996. ACCEPTED IN FINAL FORM APRIL 17, 1996.

Reprint requests to: Dr. Andres Lozano. Division of Neurosurgery, The Toronto Hospital. 399 Bathurst Street, Toronto, Ontario. Canada M5T 2S8 


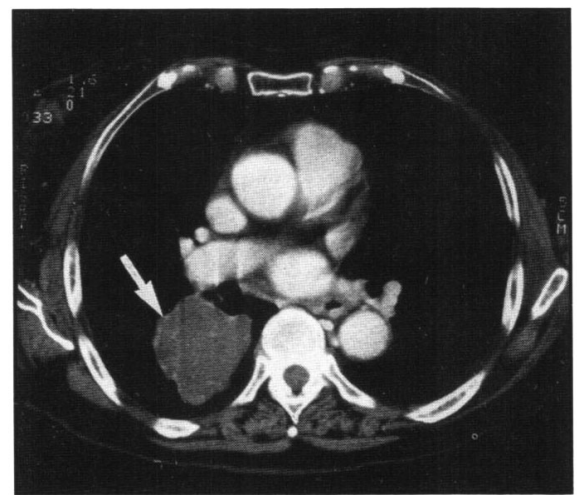

Figure 1: CT scan of the thorax demonstrates a large cavitary lesion in the right lower lobe (marked by arrow) with nodal involvement.

(Figure 2). The left cerebellar mass measured $4 \mathrm{~cm} \times 3 \mathrm{~cm} \times 3 \mathrm{~cm}$, while the right was $3 \mathrm{~cm} \times 3 \mathrm{~cm} \times 3 \mathrm{~cm}$. There was mild hydrocephalus. A preoperative radiological diagnosis of multiple cerebellar metastases or abscesses was made.

\section{Clinical Course}

To relieve neurological symptoms and to obtain a tissue diagnosis, the patient underwent a posterior fossa craniectomy. At surgery, both cerebellar hemispheres were tense and discoloured. There was extrusion of pus at corticotomy in the right cerebellum. The purulent exudate was evacuated to identify a fibrotic discrete capsule which was collapsed onto itself and was removed from the surrounding cerebellar white matter. On the left side, the lesion contained a purulent exudate but had more solid greyish components which were also excised.

Microbiological studies of this exudate revealed Gram positive cocci, identified as alpha-hemolytic streptococcus and peptococcus. Gram positive rods of beta-lactamase negative $\mathrm{H}$. Parainfluenza and Gram negative diphtheroides species were also grown. Pathological examination of tissue sections revealed solid sheets of epithelial cells with frequent pleomorphism and mitoses (Figure 3). The diagnosis was consistent with a metastatic carcinoma.

There was significant symptomatic relief of the headache, vomiting and ataxia. The antibiotic regimen was modified according to the culture reports. Palliative thoracic radiotherapy was not offered due to the terminal nature of her disease. She died of pneumonia 2 months after the surgery. Request for an autopsy was refused.

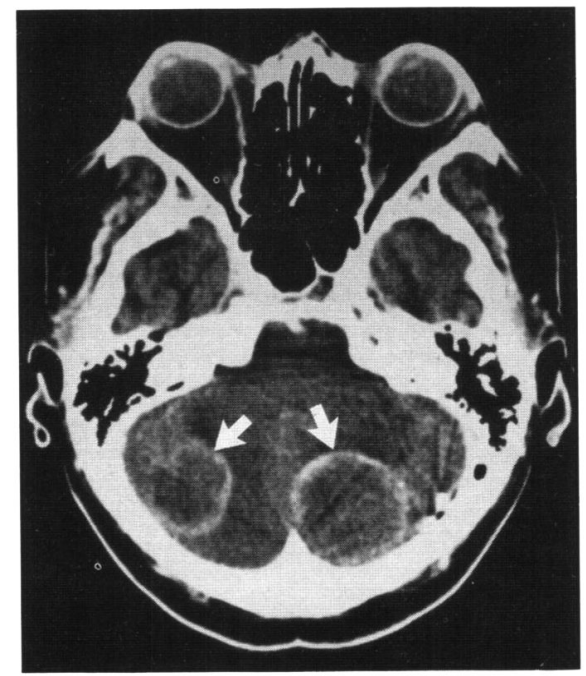

Figure 2: Contrast-enhanced CT scan shows two large ring-enhancing lesions (marked by arrows) in the posterior fossa.

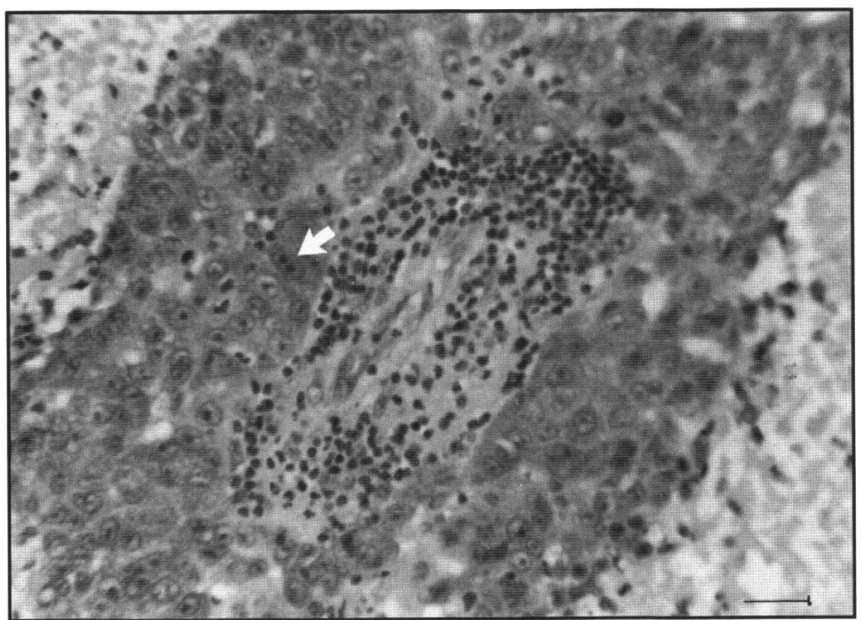

Figure 3: Photomicrograph of surgical specimen demonstrates carcinoma cells. The arrow marks a neoplastic cell with a mitotic figure. Bar $=100 \mu \mathrm{m}$.

\section{Discussion}

We report a rare case of abscess within a cerebellar metastasis. In our literature search of articles published in English since 1966 using tumour, metastasis and brain abscess as textwords, we have not found a previously reported case of a primary or secondary brain tumour coexisting with an abscess. However, a case of aspergillosis in a colonic metastasis to the pituitary gland has been documented in the Spanish literature. ${ }^{6}$

The pathophysiology of the coexisting abscess and metastasis in our patient is unknown. Possible explanations include a pure chance occurrence, hematogenous co-metastasis of tumour cells and bacteria from an infected lung neoplasm or secondary infection of a pre-existing cerebellar metastasis. The last explanation may be the most likely because necrotic tissue at the centre of a metastasis could become infected from septic hematogenous emboli. ${ }^{3}$ In this patient, the lung abscess may have been a source of bacteremia.

The organisms involved in this patient are similar to those identified in ordinary brain abscesses with streptococcus being the commonest, although Staphylococcus aureus, coliform bacilli, diphtheroides and mixed respiratory organisms can also be seen. ${ }^{3-4,7}$

CT scan with intravenous contrast has been widely used in detecting intracranial abscesses and metastases. ${ }^{2.5 .8}$ It provides useful data about the size, location, and multiplicity of lesions. Metastases usually appear as round, well encapsulated, solitary or multiple, ring-enhancing lesions at the gray/white junction, often with profound white matter edema. ${ }^{8}$ Similarly, abscesses can also present as discrete solitary or multiple ring-enhancing lesions. Therefore, radiological characteristics that differentiate abscess and metastasis are not entirely specific. For example, a biopsy-proven false positive rate of $11 \%$ in the radiological diagnosis of solitary brain metastasis has been reported. ${ }^{9}$ Radionuclide leucocyte scintigraphy has been used to detect intracranial abscesses. ${ }^{10}$ However, the false negative rate of diagnosis with this imaging modality can be as high as $20 \% 11$ and abscesses can go undetected in patients taking steroids. ${ }^{10}$ 
Metastases can be misdiagnosed at surgery if the liquefied necrotic material they may contain is mistaken for the purulent exudate of an abscess. Another error is assuming that the liquefied component represents necrotic debris and failing to consider that there may be a coexisting infection. As this case illustrates, one must consider that metastases may harbour infected material and that an abscess can contain tumour cells. Conventional radiological investigations in patients with a brain metastasis or abscess can miss important diagnostic information. This report emphasizes the potential pitfalls of empirical treatment based on radiological diagnosis alone. Optimal therapy requires proper tissue diagnosis obtained through pathological and microbiological examinations in those cases where the lesion could be either an abscess or a metastasis.

\section{REFERENCES}

1. Weiss HD, Richardson EP. Solitary brainstem metastasis. Neurology 1978; 28: 562-566.

2. Whelan WA, Hilal SK. Computerized tomography as a guide in the diagnosis and follow-up of brain abscesses. Radiology 1980; 135: 663-664.
3. Garvey G. Current concepts of bacterial infections of the central nervous system: bacterial meningitis and bacterial brain abscess. J Neurosurg 1983; 59: 735-744.

4. Lebean J, Creissand P. Surgical treatment of brain abscesses and subdural empyema. J Neurosurg 1972; 38: 198-199.

5. Rotheram EB Jr, Kessier LA. Use of computerized tomography in non-surgical management of brain abscess. Arch Neurol 1979; 36: $25-28$.

6. Stalldecker G, Molina HA, Antelo N, et al. Hypopituitarism caused by colonic carcinoma metastasis associated with hypophyseal aspergillosis. Medicina 1994; 54: 248-252.

7. Stephanov S. Surgical treatment of brain abscesses. Neurosurgery 1988; 22: 724-730.

8. Rosenblum MI, Hoff JT, Norman D. Decreased mortality from brain abscess since the advent of computerized tomography. J Neurosurg 1978; 49: 658-659.

9. Patchell RA, Tibbs PA, Walsh JW, et al. A randomized trial of surgery in the treatment of single metastases to the brain. $\mathrm{N}$ Engl J Med 1990; 322: 494-500.

10. Schmidt KG, Rasmussen JW, Frederiksen PB, et al. Indium-111granulocyte scintigraphy in brain abscess diagnosis: limitations and pitfalls. J Nucl Med 1990; 31: 1121-1127.

11. Rehncrona S, Brismar J, Holtas S. Diagnosis of brain abscesses with indium-111-labelled leukocytes. Neurosurgery 1985; 16: 23-26. 